\title{
GaMificaÇÃo NA SALA DE AULA: AVAliaÇÃo DA MOTIVAÇÃO UTILIZANDO O QUESTIONÁRIO ARCS
}

\author{
GAMIFICATION IN THE CLASSROOM: ASSESSMENT OF MOTIVATION USING \\ THE ARCS QUESTIONNAIRE
}

DOI: http://dx.doi.org/10.23926/RPD.2526-2149.2020.v5.n1.p374-390.id632

\author{
João Batista da Silva \\ Doutorando em Educação \\ (UECE) \\ joaobathista82@hotmail.com
}

\begin{abstract}
Resumo: Este artigo apresenta um recorte de uma pesquisa de pósgraduação stricto sensu. Seu objetivo é investigar a qualidade da motivação proporcionada pela gamificação nas aulas de óptica geométrica, um ramo da Física. Com relação aos aspectos metodológicos, foi realizado um estudo de caso com 16 alunos. Para avaliar a motivação, foi utilizada a Escala de Motivação de Materiais Instrucionais (IMMS), proposta por John Keller no modelo de motivação ARCS (Atenção, Relevância, Confiança e Satisfação). Os resultados mostraram uma alta porcentagem de concordância nas quatro categorias, revelando que os alunos se mostraram mais autoconfiantes, por perceber que estavam progredindo pelo seu próprio esforço, e se sentiram satisfeitos por concluírem as missões propostas. Isto posto, é possível concluir que a gamificação da sala de aula forneceu evidências empíricas suficientes para atestar que sua implementação motivou os alunos.
\end{abstract}

Palavras-chave: Gamificação; Motivação; ARCS; Ensino de Física.

\begin{abstract}
This article presents a research cut of a stricto sensu postgraduate. Its purpose is to investigate the quality of motivation provided by gamification in geometric optics classes, a branch of Physics. Regarding the methodological aspects, a case study was carried out with 16 students. In assessing motivation, the Instructional Materials Motivation Scale (IMMS), proposed by John Keller in the ARCS motivation model (Attention, Relevance, Confidence, Satisfaction), was used. The results showed a high percentage of agreement in the four categories, revealing that the students were more self-confident, as they realized that they were progressing through their own effort, and were satisfied with completing the proposed missions. That said, it is possible to conclude that the gamification of the classroom provided sufficient empirical evidence to attest that its implementation motivated the students.
\end{abstract}

Keywords: Gamification; Motivation; ARCS; Physics education. 


\section{INTRODUÇÃO}

Dificuldades encontradas por alunos na compreensão de conceitos científicos de óptica geométrica estão relacionadas ao ensino desvinculado de aspectos físicos ligados à natureza da luz, do processo de visão e, principalmente de assuntos relacionados ao cotidiano do aluno. Isto acaba gerando desmotivação, que tem sido um dos principais desafios da atualidade para o ensino de Física, principalmente na Educação Básica.

Diante desse cenário contemporâneo, Müller et al., 2017 destacaram que este não é um problema apenas do ensino de Física, mas, também, de outras áreas com Química, Biologia, Matemática, entre outras.

Diante dessa problemática, têm surgido algumas estratégias/alternativas didáticas no ensino de Física, dentre elas a gamificação, cujo propósito é motivar e engajar os alunos no processo de aprendizagem (SILVA; SALES; 2017b; TOLENTINO; ROLEDA, 2017), e em particular, para o ensino de óptica (SALES et al., 2017; SILVA; SALES; 2017a). Não obstante, vale destacar que, apesar das pesquisas apontarem os benefícios da gamificação para engajar e motivar os discentes na aprendizagem, a maioria das pesquisam não fornece evidências empíricas suficientes para atestar os efeitos benéficos da gamificação implementada, principalmente, por não apresentarem o aporte teórico adequado para investigar benefícios comportamentais como motivação e engajamento (TODA; SILVA; ISOTANI, 2017).

Considerando esta carência na literatura, o objetivo dessa pesquisa é investigar a qualidade da motivação proporcionada pela gamificação nas aulas de óptica geométrica, numa turma de Ensino Médio, por meio do questionário modelo ARCS desenvolvido por John Keller.

Este artigo está organizado da seguinte forma; na introdução foram apresentados a problemática e o objetivo de pesquisa; na seção 2, será exposto o significado do termo gamificação; na seção 3, é apontada a metodologia de pesquisa; na seção 4, serão apresentados e discutidos os resultados da pesquisa; por fim na seção 5, serão apresentadas as considerações finais.

\section{REFERENCIAL TEÓRICO}

A definição do termo gamificação foi cunhada por Deterding et al. (2011) como sendo a utilização de elementos de design de jogos, em contextos que não seja, necessariamente, jogos, para motivar as pessoas, aumentar sua atividade e reter sua atenção. Como exemplo desses elementos, Fardo (2013) elencou alguns; voluntariedade, regras claras, objetivos, 
feedback imediato, motivação, competição, recompensas, níveis, inclusão do erro no processo, diversão, narrativa, abstração da realidade, conflito, cooperação, entre outros.

Esses são elementos que devem estar presentes num bom game, portanto, devem ser incorporados na gamificação. Todavia, vale ressaltar que não é obrigatório utilizar todos esses elementos simultaneamente em apenas uma atividade, contudo, há alguns que são essenciais. Nesse sentido, McGonigal (2011) destacou que de todos os elementos, quatro são imprescindíveis em qualquer game: voluntariedade, regras, objetivos e feedbacks. A voluntariedade implica a aceitação das regras, objetivos e feedbacks. Quanto aos objetivos, estes devem ser claros, pois direcionam o usuário a se concentrar para atingir o propósito. As regras servem para condicionar as ações do jogador, ou seja, definir a maneira como ele deverá se comportar (VIANNA et al., 2013). Já os feedbacks devem ser imediatos, claros e diretos, pois têm como função informar aos jogadores como está sua relação em relação aos objetivos e/ou demais jogadores.

No contexto da aprendizagem, a gamificação é vista como a utilização das mecânicas, estética e pensamentos dos games para envolver pessoas, motivar a ação, promover a aprendizagem e resolver problemas (ZICHERMANN; CUNNINGHAM, 2011; KAPP, 2012).

Vale destacar que a estratégia de utilizar gamificação na educação para motivar e potencializar o processo de aprendizagem, tem sido amplamente investigada (FARDO, 2013; SILVA; SALES, 2017a; SILVA; SALES, 2017b).

Apesar da pesquisa de Silva e Sales (2017b) apresentarem um crescimento exponencial nos últimos anos de pesquisas sobre gamificação aplicada para motivar a aprendizagem, vale ressaltar que, ainda há uma enorme carência de trabalhos que utilizem instrumentos e métricas psicométricas adequados e validados para avaliar seus reais efeitos na motivação dos alunos (HAMARI; KOIVISTO; SARSA, 2014).

Esta carência dificulta ainda mais o trabalho do professor, que além de tentar estimular e manter a motivação do aluno na sala de aula, ainda tem a dificuldade de encontrar métodos confiáveis e válidos para fazer isto (KELLER, 2009).

Diante dessa lacuna, esta pesquisa se propõe a investigar a qualidade da motivação utilizando para isso métodos confiáveis e válidos. Isto posto, na próxima seção será apresentada a metodologia de pesquisa que será utilizada na presente investigação. 


\section{Metodologia}

Com relação aos aspectos metodológicos da pesquisa, optou-se por uma abordagem metodológica da pesquisa qualitativa. Com relação aos procedimentos técnicos, resolveu-se realizar um estudo de caso. Segundo Yin (2001) o estudo de caso é uma estratégia de pesquisa empírica, cujo objetivo é investigar um tópico específico, como por exemplo, um fenômeno contemporâneo dentro de seu contexto da vida real envolvendo muitas variáveis, principalmente, quando os limites entre o fenômeno e o contexto não estão claramente definidos. Uma das características do estudo de caso é que ele deve seguir um conjunto de procedimentos pré-especificados envolvendo planejamento, coleta de dados e análise de dados.

O universo da pesquisa foi composto por 16 alunos do Ensino Médio do curso de Técnico Integrado em eletrotécnica do IFCE (Instituto Federal de Educação, Ciência e Tecnologia do Ceará). O instrumento de coleta de dados utilizado foi o questionário. Como a intenção dessa pesquisa foi obter um resultado rigoroso, a condição estabelecida foi que o pesquisador não lecionasse no ambiente de pesquisa. Essa condição foi estabelecida para que a interferência do pesquisador fosse mínima, restringindo-se apenas a observação na sala de aula e a coleta de dados. O objetivo dessa restrição fundamenta-se na necessidade de garantir, ao resultado dos dados coletados, a mínima influência possível atrelada a algum viés do pesquisador.

O conteúdo de Física estudado foi óptica geométrica. Esse ramo da Física tem como tema principal a investigação dos fenômenos luminosos envolvendo o estudo da luz, partindo do pressuposto de que ela se propaga de forma retilínea em uma direção fixa em um meio uniforme, porém, poderá mudar de direção se incidir obliquamente em uma superfície de um meio diferente, ou se o mesmo meio apresentar propriedades ópticas não uniformes no espaço ou no tempo (JEWETT; SERWAY, 2012).

Quanto a metodologia de ensino gamificada, incialmente, foi definido e apresentado para os alunos o contrato didático (regras, objetivos, missões, pontuação, entre outros).

\subsection{REGRAS DO JOGO}

Nessa etapa, foram esclarecidos quais seriam os tópicos/conteúdos, prazos, tipos de avaliação, missões (atividades) em grupo/times e individuais. De acordo com Vianna et al. (2013) a função das regras é definir a maneira que o jogador deverá se comportar para alcançar seus objetivos. Ou seja, como ele deverá organizar suas ações para o cumprimento dos desafios impostos pelo jogo. 


\subsection{OBJETIVOS}

Quantos aos objetivos foi estabelecido que cada aluno deveria cumprir as missões e superar os desafios propostos para conquistar a maior pontuação possível. Essa é uma das características dos games, em que o objetivo é o motivo que justifica a realização das atividades por parte dos jogadores, de maneira que haja intensa concentração para atingir os propósitos designados (VIANNA et al., 2013).

\subsection{AS MISSÕES}

As missões propostas foram divididas em simples e complexas. Entre as missões simples foram propostas a construção de um glossário hipertextual ${ }^{1}$, atividade experimental utilizando prisma óptico, lista de exercícios e simulações computacionais utilizando a plataforma $P H E T^{2}$. Algumas missões mais complexas (situações-problema) foram divididas em missões menores em ordem crescente de complexidade, para possibilitar o cumprimento e proporcionar aos alunos senso de crescimento e progressão.

\subsection{Pontos}

O sistema de pontos utilizado foi o de pontos de experiência (eXperience Points $-X P$ ), que consiste na pontuação cedida através da realização das atividades pelo aluno. Desta forma, a cada tarefa/questão realizada, o aluno garante uma quantia de XP que, conforme vai sendo acumulada, é reflletida na evolução do personagem, aumentando seu nível e, consequentemente, tornando o aluno apto a superar desafios cada vez mais difíceis (FARDO, 2013). A conversão de pontos em nota, se faz necessário porque o sistema da instituição de ensino utiliza notas como referência para avaliar o desempenho dos alunos.

\subsection{FEEDBACKS}

Por fim, para tornar o plano da disciplina ainda mais claro para os alunos foi utilizada a plataforma Help Class Online. Este recurso foi utilizado para que o aluno pudesse acompanhar seu desempenho e para auxiliar o professor no gerenciamento da avaliação da aprendizagem, por meio de feedbacks imediatos de suas ações intencionais logo após o cumprimento de cada

\footnotetext{
${ }^{1}$ Esta atividade tem por objetivo a construção coletiva de um glossário de termos técnicos relacionados à área de estudo da óptica geométrica para posterior utilização em consultas.

${ }^{2}$ O PHET é uma plataforma, fundada em 2002 pelo Prêmio Nobel Carl Wieman, cujo objetivo é criar e disponibilizar simulações computacionais interativas gratuitas de matemática e ciências. Esta plataforma está disponível no endereço: https://phet.colorado.edu/pt_BR/.
} 
missão específica. De acordo com Domínguez et al. (2013), fornecer feedbacks imediatos para os alunos é uma das principais dificuldades encontradas por professores em atividades gamificadas. Considerando esta dificuldade, algumas pesquisas (KAMINSKI; SILVA; BOSCARIOLI, 2018; SILVA et al., 2018) tem utilizado alguns recursos digitais para fornecer feedback imediato, como por exemplo o Kahoot, uma ferramenta de avaliação gamificada.

\section{Resultados}

Conforme descrito na seção precedente, para avaliar a motivação do aluno, foi aplicado o modelo de questionário baseado no modelo ARCS. O questionário utilizado no ARCS foi o Instructional Materials Motivation Scale (IMMS), composto por 36 assertivas distribuídas nas quatro categorias citadas nos parágrafos anteriores. Analogamente às pesquisas de Savi (2011) e Poffo (2016), optou-se por não criar ou gerar novos itens, mas apenas aproveitar 16 das 36 assertivas, as quais, por necessidade, foram adaptadas para que pudessem atingir o objetivo desta pesquisa, que é verificar a motivação proporcionada pela gamificação. A classificação dos itens segue os mesmos critérios anteriormente adotados no IMMS (Quadro 1).

Quadro 1 - Instrumento de avaliação da qualidade da motivação baseado no IMMS

\begin{tabular}{|c|c|c|}
\hline Categoria & & Assetivas \\
\hline \multirow{4}{*}{ Atenção } & Q1 & Houve algo interessante no início das aulas que chamou minha atenção. \\
\hline & $\mathrm{Q} 2$ & O design da sala de aula é atraente. \\
\hline & Q3 & Aprendi algumas coisas surpreendentes ou inesperadas. \\
\hline & Q4 & $\begin{array}{l}\text { A variedade de recursos utilizados (computador, simuladores, exercícios, } \\
\text { desafios, quizzes, entre outros) ajudou a manter minha atenção nas aulas. }\end{array}$ \\
\hline \multirow{4}{*}{ Relevância } & Q5 & $\begin{array}{l}\text { Ficou claro para mim que o conteúdo das aulas está relacionado às coisas } \\
\text { que eu já conhecia. }\end{array}$ \\
\hline & Q6 & O conteúdo das aulas é relevante para os meus interesses. \\
\hline & Q7 & $\begin{array}{l}\text { Houve explicações ou exemplos de como as pessoas usam/aplicam o } \\
\text { conhecimento desta disciplina. }\end{array}$ \\
\hline & Q8 & O conteúdo desta lição será útil para mim. \\
\hline \multirow{4}{*}{ Confiança } & Q9 & $\begin{array}{l}\text { Quando examinei pela primeira vez o conteúdo da disciplina, tive a } \\
\text { impressão de que seria fácil para mim. }\end{array}$ \\
\hline & Q10 & $\begin{array}{l}\text { Depois de ler as informações introdutórias, fiquei mais confiante por saber o } \\
\text { que eu deveria aprender durante as aulas. }\end{array}$ \\
\hline & Q11 & $\begin{array}{l}\text { Ao passar pelas etapas das atividades senti confiança de que estava } \\
\text { aprendendo o conteúdo. }\end{array}$ \\
\hline & Q12 & A boa organização das aulas me ajudou a ter certeza de que eu aprendi. \\
\hline \multirow{4}{*}{ Satisfação } & Q13 & Concluir esta lição com sucesso foi importante para mim. \\
\hline & Q14 & Concluir os exercícios nesta disciplina me deu uma satisfação de realização. \\
\hline & Q15 & $\begin{array}{l}\text { Foi por causa do meu esforço pessoal que consegui avançar na } \\
\text { aprendizagem, por isso me sinto recompensado. }\end{array}$ \\
\hline & Q16 & Gostei tanto dessa disciplina que gostaria de saber mais sobre ela. \\
\hline
\end{tabular}

Fonte: Adaptado de Keller (2009) 
O questionário ARCS apresenta em sua configuração inicial quatro categorias/indicadores sobre a qualidade da motivação do aluno no contexto educacional, no qual os participantes da avaliação darão respostas conforme seu grau de concordância com a assertiva a partir de uma escala Likert de cinco pontos em cada assertiva: 'Discordo totalmente' (DT), 'Discordo parcialmente' (DP), 'Indiferente'(I), 'Concordo parcialmente' (CP), 'Concordo totalmente' (CT). Dessa maneira, os alunos podem indicar se concordam ou discordam com a afirmação, designando assim, o grau de concordância.

Um passo muito importante tomado durante a implementação aplicação do questionário ARCS foram o esclarecimento sobre o anonimato do respondente e a sensibilização dos alunos para a importância da avaliação da metodologia de ensino gamificada. Além disso, vale ressaltar que no final do questionário foi deixado um espaço para que os alunos, livremente, pudessem expressar sua opinião, os pontos positivos e negativos sobre a metodologia aplicada.

O questionário foi aplicado durante a última semana de aula. É importante destacar que, a fim de evitar a interferência docente nas respostas, além do anonimato do aluno, o questionário foi aplicado na ausência do professor.

Dos 16 alunos, apenas 15 responderam ao questionário. $\mathrm{O}$ aluno $\mathrm{A} 8$ não respondeu porque esteve ausente nas últimas aulas por motivo de saúde. É importante destacar que a nomenclatura dos alunos no questionário (A1, A2, A3...) foi diferente da nomenclatura dos alunos no teste (E1, E2, E3...), isto porque foi garantido para os alunos o anonimato das respostas do questionário.

Como foi utilizado apenas 16 itens do IMMS, após a aplicação do questionário, foi verificado a consistência interna dos itens selecionados em relação à interferência das correlações destes na precisão do conjunto. Vale destacar, que o IMMS, desenvolvido por Keller para uso em seu modelo ARCS, já foi validado por meio de testes psicométricos, o que aumenta a sua confiabilidade para medir o nível de motivação. Todavia, como algumas assertivas foram retiradas, fez-se necessário calcular o coeficiente alfa de Cronbach, que de acordo com Savi (2011) é considerado um dos indicadores mais importantes da qualidade de uma escala de medida.

O coeficiente $\alpha$ de Cronbach é calculado pela seguinte equação:

$$
\alpha=\left(\frac{k}{k-1}\right)\left(1-\frac{\sum_{i=1}^{k} S_{i}^{2}}{S_{t}^{2}}\right)
$$




\section{Em que:}

$k$ é o número de Assertivas.

$n$ é o número de respondentes.

$S^{2}{ }_{i}$ é a ${ }^{2}$ variância dos $n$ escores das pessoas a $i$-ésimo item $(i=1, \ldots, k)$.

$S_{t}^{2}$ é a variância dos totais $T j(j=1,2, \ldots, n)$.

Os valores do coeficiente $\alpha$ de Cronbach podem variar entre 0 e 1 , sendo que os valores próximos de 0 (zero) indicam baixa consistência interna e os valores próximos de 1 (um) indicam boa consistência. Em síntese, para que um questionário tenha consistência interna considerável e válida, deve ter valores de $\alpha>0,7$ (SAVI, 2011).

Considerando o parâmetro preestabelecido, os resultados mostraram que o questionário possui alta confiabilidade ( $\alpha=0,795)$, sendo, portanto, considerado válido para investigar o nível de motivação. Sendo assim, a análise do questionário será baseada na proposta de Savi (2011) e Poffo (2016) que apontaram que a interpretação dos dados deverá está diretamente ligada ao formato de resposta dos itens, que, no caso deste trabalho, consiste em uma escala que vai de 1 até 5 . Sendo que, quanto maior for a porcentagem de respostas 4 (Concordo parcialmente) e 5 (Concordo totalmente) nas quatro categorias (Atenção - Relevância Confiança - Satisfação), melhor avaliada será o nível de motivação proporcionada pela metodologia.

\subsection{ATENÇão}

Os resultados mostraram que a metodologia utilizada despertou a atenção dos alunos, o que é essencial para motivar a aprendizagem (KELLER, 2009; SAVI, 2011).

Desta forma, pelo grau de concordância na assertiva Q1 de 100\%, é possível perceber que no início das aulas foi realizado alguma atividade que chamasse/despertasse a atenção do aluno (Figura 1). Este resultado é superior ao encontrado por Poffo (2016) que obteve um

Figura 1 - Avaliação da categoria atenção sobre a qualidade da motivação

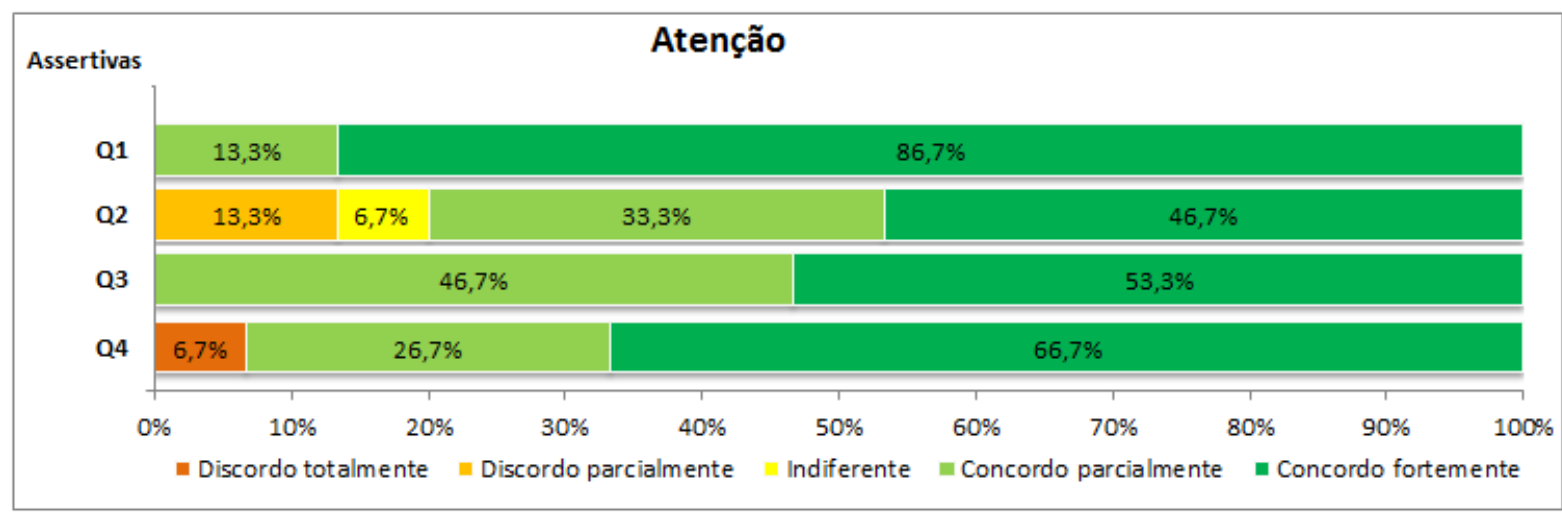

Fonte: Elaboração própria 
$\mathrm{Na}$ assertiva Q2 é possível verificar que o design da sala era atraente, pois houve concordância do grupo de $80 \%$, sendo que destes, $46,7 \%$ concordaram totalmente, $33,3 \%$ concordaram parcialmente e apenas 13,3\% discordaram parcialmente. Estes resultados são semelhantes aos encontrados por Poffo (2016) que obteve um percentual de $80,70 \%$ de concordância e 19,30\% de discordância. Uma hipótese para explicar parte dessa discordância, talvez tenha sido pelo fato dos alunos ainda não estarem acostumados ao uso de computadores em sala de aula, o que deve ter incomodado alguns. Nesse sentido, o aluno 2 destacou que:

"O professor poderia pedir para os alunos desligarem o computador enquanto não tivesse sendo utilizado. Por conta da presença dos computadores os alunos ficam um pouco dispersos, fazendo o professor perder o domínio da sala"(Aluno 2).

Por meio dessa colocação, é possível inferir que a relação professor-alunos-ambiente poderá ser repensada para receber melhorias na interface, bem como a adaptação dos alunos com as tecnologias digitais na sala de aula para fins educacionais, o que também é um grande desafio na contemporaneidade. Por outro lado, apesar de uma pequena parte do grupo não concordar com este item, isso não reflete a opinião da maioria, que concordou que o design da sala era atraente para proporcionar aprendizagem. Nesse sentido, o aluno A7 destaca:

"Os recursos utilizados são bastante interessantes, pois deixa um clima para estudo melhor, do que somente dar aula e depois aplicar provas" (Aluno 7).

Além de ser considerada atraente, a metodologia propôs ensinar coisas surpreendentes ou inesperadas (Assertiva 3), nesse sentido, é possível verificar que 100\% de concordância. Este resultado coaduna com a afirmação de Savi (2011), o qual destacou que novos obstáculos, situações e variações de atividades são importantes para minimizar a fadiga do jogador e oferecer uma experiência que mantenha sua vontade de continuar jogando, portanto, tal estratégia deve ser bem planejada.

Os resultados da quarta assertiva (Q4), com 93,4\%) de concordância, revelaram que a variedade de recursos utilizados (computador, simuladores, exercícios, desafios, quizzes, entre outros) ajudou a manter a atenção do aluno nas aulas. Este resultado foi um pouco superior ao encontrado por Poffo (2016), que obteve $82,45 \%$ de concordância dos alunos. Isto significa que as atividades, conteúdos e recursos utilizados ajudaram a manter a atenção do aluno, o que é uma condição inicial para motivar a aprendizagem. Esta condição é confirmada na citação do Aluno 9.

"O sistema de quizzes estimulam o aluno a se manter estudando, pois não sabemos quando vai haver quiz"(Aluno 9). 
Por fim, embora a atenção tenha sido bem avaliada, ela é uma condição necessária, mas não suficiente para que haja motivação dos alunos, por isso, é importante que os conteúdos, além de despertarem a atenção dos alunos, sejam relevantes.

\subsection{RELEVÂNCIA}

O objetivo desta categoria é investigar se o conteúdo ensinado é relevante/importante para o aluno. Segundo Savi (2011, p. 108) o aluno precisa perceber que a proposta educacional é importante para o seu futuro profissional ou acadêmico.

$\mathrm{Na}$ Figura 2, é possível perceber que os resultados da quinta assertiva (Q5) mostraram uma concordância foi de $100 \%$, sendo que 33,3\% concordaram parcialmente e 66,7\% concordaram parcialmente, evidenciando, portanto, que o conteúdo das aulas está relacionado às coisas do seu cotidiano do aluno, ou seja, aquilo que ele já conhece previamente.

Figura 2 - Avaliação da categoria relevância sobre a qualidade da motivação

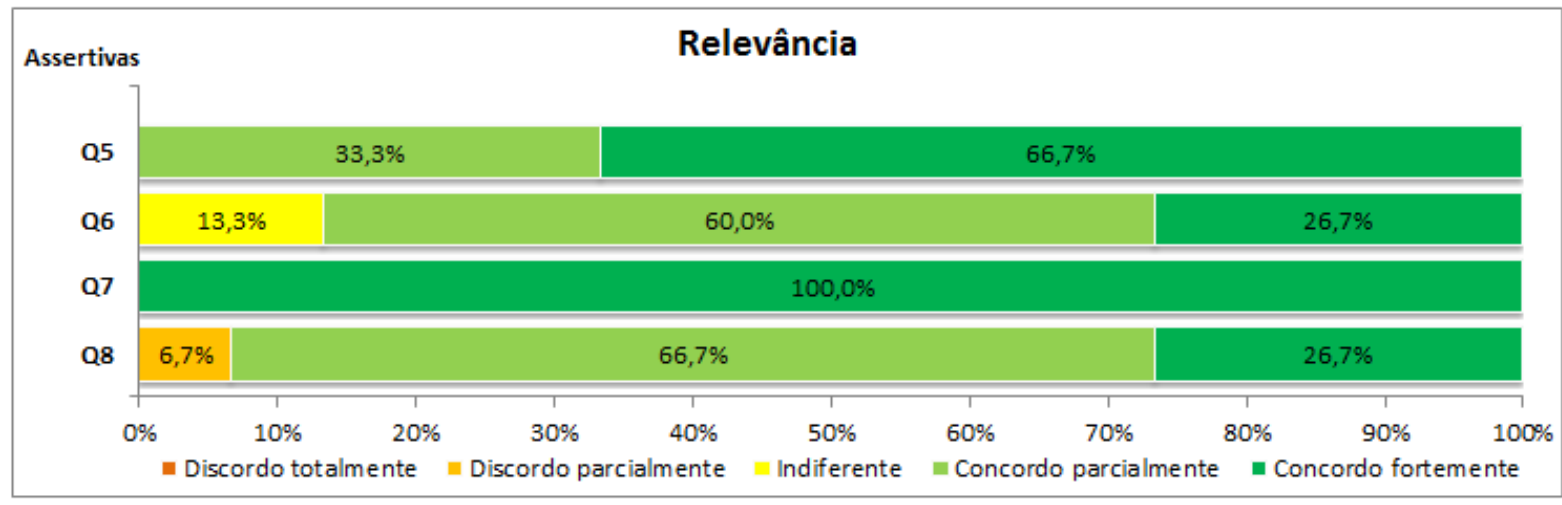

Fonte: Elaboração própria

Considerando que a maioria dos alunos concordaram $(86,7 \%)$ com a assertiva Q6, é possível inferir que foi o conteúdo das aulas foi considerado relevante para o interesse dos alunos. Este resultado foi um pouco superior à porcentagem de concordância encontrado por Poffo (2016) que foi de 71,93\%. É importante destacar que não houve discordância, apenas $13,3 \%$ do grupo permaneceu indiferente a esta questão. Acredita-se que este resultado tenha sido influenciado pelo fato de que os alunos investigados estejam no último período do curso, e consequentemente, a maioria está preocupando-se com o vestibular/ENEM.

A assertiva Q7 foi a mais bem avaliada do questionário obtendo concordância total de $100 \%$. Isto mostra que durante as aulas houve explicações ou exemplos de como as pessoas usam/aplicam o conhecimento desta disciplina.

Já a assertiva oito (Q8) teve como objetivo saber se o conteúdo ministrado seria útil para a vida pessoal do aluno. Conforme é possível observar na Figura 2, o nível de concordância foi 
bem alto, chegando a 93,4\% de concordância, sendo que, $66,7 \%$ concordaram parcialmente e $26,7 \%$ concordaram totalmente. Apenas, 6,6\% do grupo discordaram parcialmente desta assertiva. Como o grupo observado está cursando o último semestre do curso técnico integrado em eletrotécnica, sendo este um curso cuja proposta é preparar o jovem para o mercado de trabalho, acredita-se que esta pequena parte que discordou possa considerar o estágio ou o trabalho, em si, mais útil para a sua vida pessoal. Por meio dos resultados obtidos nessa categoria, é possível inferir que os conteúdos ministrados, quando relacionados aos conhecimentos que o aluno conhecia, juntamente com as explicações pelo professor de como as pessoas aplicam o conhecimento desta disciplina, foram relevantes para proporcionar motivação. Por fim, acredita-se que a percepção do aluno sobre a importância do conteúdo é um elemento fundamental para o desenvolvimento de atitudes motivacionais. Das quatro categorias, a Relevância foi a mais bem avaliada. Mesmo assim, ela por si só, também não garante que haja motivação, sendo também necessário que haja confiança.

\subsection{CONFIANÇA}

O objetivo dessa categoria foi investigar se a metodologia aplicada estimulou a autoconfiança nos alunos. Uma síntese dos resultados está apresentada na Figura 3.

Figura 3 - Avaliação da categoria confiança sobre a qualidade da motivação

\begin{tabular}{|c|c|c|c|c|c|c|c|c|c|c|c|}
\hline \multirow{2}{*}{$\begin{array}{r}\text { Assertivas } \\
\\
\text { Q9 }\end{array}$} & \multicolumn{11}{|c|}{ Confiança } \\
\hline & \multicolumn{3}{|c|}{$20,0 \%$} & \multicolumn{3}{|c|}{$40,0 \%$} & \multicolumn{3}{|c|}{$26,7 \%$} & \multicolumn{2}{|c|}{$13,3 \%$} \\
\hline Q10 & $6,7 \%$ & $13,3 \%$ & & \multicolumn{3}{|c|}{$40,0 \%$} & \multicolumn{5}{|c|}{$40,0 \%$} \\
\hline Q11 & \multicolumn{8}{|c|}{$73,3 \%$} & \multicolumn{3}{|c|}{$26,7 \%$} \\
\hline \multirow[t]{2}{*}{ Q12 } & $6,7 \%$ & \multicolumn{5}{|c|}{$53,3 \%$} & \multicolumn{5}{|c|}{$40,0 \%$} \\
\hline & & $10 \%$ & $20 \%$ & $30 \%$ & $40 \%$ & $50 \%$ & $60 \%$ & $70 \%$ & $80 \%$ & $90 \%$ & $100 \%$ \\
\hline \multicolumn{4}{|c|}{ Discordo totalmente } & ordo pa & Imente & Indiferente & Conc & parcia & \multicolumn{3}{|c|}{ te Concordo fortemente } \\
\hline
\end{tabular}

Fonte: Elaboração própria

Os resultados mostraram que os alunos, ao examinaram pela primeira vez o conteúdo da disciplina, não tiveram a impressão de que o conteúdo seria fácil. Vale destacar que este foi o item de todo o questionário que obteve menor aceitação, tendo, portando, apenas $40 \%$ de concordância (13,3\% totalmente e 26,7\% parcialmente). Por meio destes resultados é possível perceber que apesar da literatura (AGUIAR, 2009) mostrar que a óptica geométrica é um campo 
com importantes aplicações práticas que deveriam facilitar a aprendizagem, a concepção inicial do grupo em relação ao material foi bem diferente.

O objetivo da décima assertiva (Q10) foi investigar se alunos ao lerem as informações introdutórias da lição ficaram mais confiantes por saberem sobre o que deveriam aprender durante as aulas. Os resultados mostraram que a maioria do grupo realmente leu o material, e apesar de não acharem o conteúdo tão fácil, $80 \%$ do grupo concordaram com a assertiva.

A finalidade da décima primeira questão (Q11) foi pesquisar se quando os alunos passaram pelas etapas das atividades eles sentiram confiança de que estavam aprendendo o conteúdo. Esta foi a assertiva mais bem avaliada dessa categoria com 100\% concordância (26,7\% concordaram parcialmente e 73,3\% concordaram parcialmente). Acredita-se que este resultado tenha sido diretamente influenciado pela forma com que as missões foram propostas em níveis progressivos de complexidade. Segundo Busarello (2016), estruturar níveis de dificuldades progressivas permite, paralelamente, o crescimento dos níveis de habilidades do sujeito, para que a atividade não se torne desinteressante.

A influência dos efeitos positivos desse tipo de estrutura também é evidenciada na assertiva doze (Q12) com 93,3\% de concordância (40\% concordaram totalmente $40 \%$ e $53,3 \%$ concordaram parcialmente), quando é questionado se a organização das aulas ajudou a na aprendizagem. Este resultado coaduna com o pressuposto de Busarello (2016) de que os alunos tendem a estar mais motivados quando sentem que podem aprender sozinhos com o seu próprio material didático.

Diante desses resultados, acredita-se que a boa organização das aulas é essencial para ajudar na motivação, pois os alunos precisam acreditar que serão capazes de desenvolver as atividades propostas, avançar e controlar seu o próprio sucesso (SILVA; DUBIELA; 2014).

Por fim, como esta categoria foi bem avaliada, pode-se afirmar que a atividade gerou confiança nos alunos, todavia, como as demais categorias anteriormente avaliadas, ela é necessária, mas não é suficiente. Para se afirmar que houve motivação, portanto, é necessário, também, que haja satisfação na realização das atividades.

\subsection{Satisfação}

A satisfação é um sentimento subjetivo do aluno que está associada com o sentido de realização de algo (completar tarefas, superar desafios difíceis, derrotar oponentes, desenvolver e testar habilidades, alcançar objetivos, entre outros) que ocorre na relação entre habilidades 
individuais e desafios (BUSARELLO, 2016). A seguir serão apresentados os resultados para esta categoria na Figura 4.

Figura 4 - Avaliação da categoria satisfação sobre a qualidade da motivação

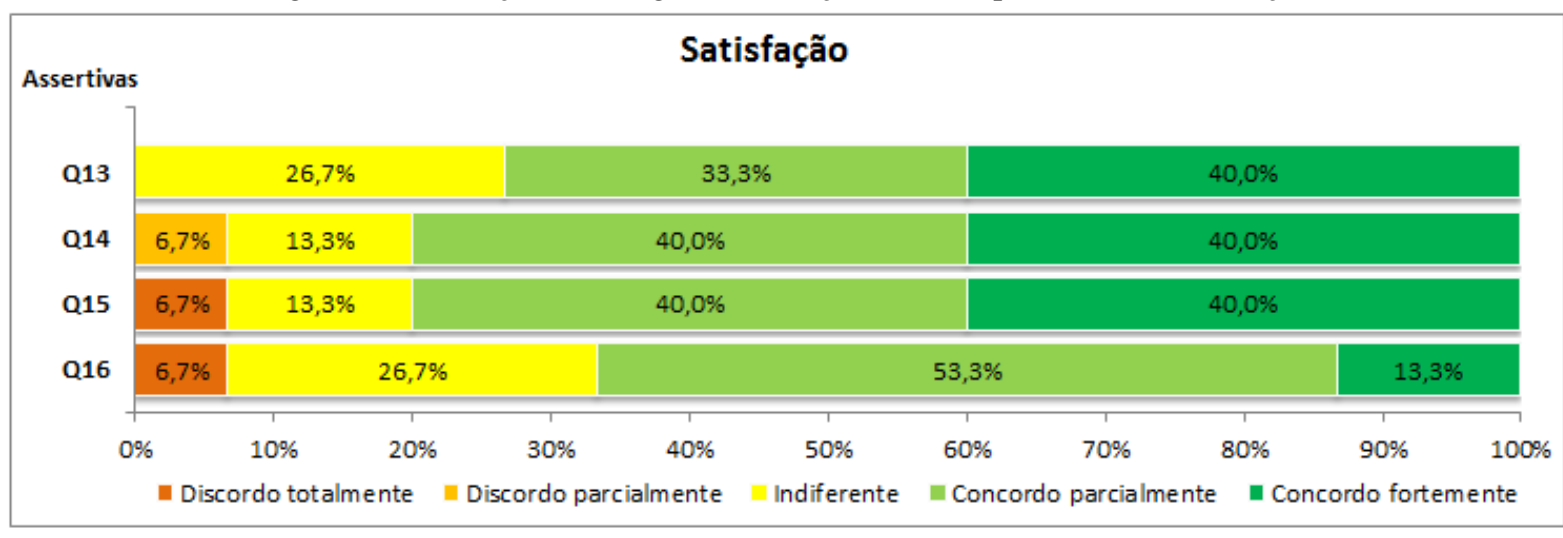

Fonte: Elaboração própria

Os resultados da assertiva Q14 mostraram que, para o aluno, concluir a lição com sucesso foi muito importante. Esta categoria teve um nível de concordância moderado (73,3\%), contudo, vale destacar que o nível de indiferença foi relativamente alto $(26,7 \%)$, por outro lado, não houve discordância. Estes resultados foram semelhantes ao evidenciado na décima quarta assertiva (Q14) ao constatar que os alunos tiveram uma satisfação de realização ao concluírem os exercícios da disciplina, com $80 \%$ de concordância por parte da turma. Por meio destes resultados é possível inferir que a autoavaliação do aluno em relação à importância do conteúdo que ele está aprendendo, bem como a conclusão das missões, é um fator impulsionador da satisfação, a qual poderá influenciar os alunos a alcançarem seus objetivos pré-definidos ao realizar uma atividade.

A assertiva Q15 objetivou investigar se foi por causa de seu esforço pessoal que os alunos conseguiram avançar na aprendizagem, e por isso se sentiram recompensados. Essa assertiva teve $80 \%$ de concordância, resultado idêntico ao da assertiva Q14. Para Busarello (2016), a compreensão por parte do aluno, de que seu esforço vai auxiliar no processo de aprendizagem fornecerá significado ao aluno sobre o novo conhecimento que vem sendo apreendido, o que é essencial para a motivação e engajamento do sujeito.

Já a assertiva dezesseis (Q16) teve o propósito pesquisar se os alunos tinham gostado da disciplina e gostaria de saber mais sobre ela. A aceitação dessa assertiva foi relativamente baixa, quando comparada com as demais. Observou-se que apenas 66,6\% dos informantes disseram concordar. O nível de indiferença deste item foi relativamente alto alcançando $26,7 \%$ e a rejeição foi apenas de $6,7 \%$. Acredita-se que a baixa aceitação deste item tenha sido 
influenciada pelas poucas aulas práticas experimentais no laboratório de Física que houve. Nesse sentido, o aluno A3 destaca:

"Metodologia nova ajuda na concentração da aula e incentiva a pesquisa. Mas a abordagem prática é o melhor ponto de qualquer aula de Física (Aluno A3)".

Apesar da proposta da metodologia de utilizar os mais diversos recursos, foi evidenciado que alguns alunos preferem aula com laboratório real de Física. Este fato ficou evidente nas colocações do aluno A3, que ao expressar os pontos positivos da metodologia, colocou:

Em suma, os resultados desta categoria mostraram que o nível de satisfação foi moderado. Já o resultado do questionário evidenciou que, de maneira geral, as categorias tiveram um resultado bastante positivo na avaliação motivacional. Foi evidenciado que houve aumento do desejo em alcançar objetivos durante o aprendizado, do interesse em aprender conteúdos relevantes e da autoconfiança ao sentirem que estavam progredindo pelo seu próprio esforço, proporcionando assim, a satisfação de realização. Por fim, considerando que o instrumento de investigação foi considerado válido para investigar a motivação dos alunos, é possível concluir que a estratégia de gamificar a sala de aula motivou os alunos.

\section{CONSIDERAÇÕES FINAIS}

O objetivo dessa pesquisa foi investigar a qualidade da motivação proporcionada pela gamificação nas aulas de óptica geométrica, numa turma de Ensino Médio, por meio do questionário modelo ARCS, desenvolvido por John Keller. Esse modelo avalia quatro categorias (atenção, relevância, confiança e satisfação) que representam um conjunto de condições necessárias para uma pessoa possa ser totalmente motivada.

O valor do coeficiente $\alpha$ de Cronbach encontrado $(\alpha=0,795)$ ratificou a boa consistência interna, confiabilidade e validade do questionário para investigar o nível de motivação. Os resultados mostraram uma da alta porcentagem de concordância com as assertivas, evidenciando, portanto, que os alunos demonstraram maior interesse em aprender os conteúdos relevantes de Física, mostraram-se mais autoconfiantes por perceber que estavam progredindo pelo seu próprio esforço, e sentiram-se satisfeitos por concluírem as missões propostas. Estes resultados apresentados fornecem evidências empíricas suficientes para atestar que a estratégia de gamificar a sala de aula motivou os alunos.

Por fim, acredita-se que apenas utilizar a gamificação na sala de aula, por si só, não garante que a motivação esteja adequada e alinhada aos objetivos educacionais, portanto, é 
necessário, também, que ela esteja alinhada como metodologias de ensino que sejam adequadas e consistentes.

\section{REFERÊNCIAS}

BUSARELLO, Raul Inácio.Gamification: princípios e estratégias. 1. ed. São Paulo: Pimenta Cultural, 2016.

DETERDING, Sebastian. et al. From game design elements to gamefulness: defining "gamification". In: MindTrek '11: Proceedings of the 15th International Academic MindTrek Conference: Envisioning Future Media Environments, 15, 2011, Tampere. Proceedings... New York: Acm, 2011.p. 9 - 15. DOI: https://doi.org/10.1145/2181037.2181040.

DOMÍNGUEZ, Adrián. et al. Gamifying learning experiences: practical implications and outcomes. Computers and Education, v. 63, p. 380-392, 2013. DOI:

https://doi.org/10.1016/j.compedu.2012.12.020.

FARDO, Marcelo Luís. A gamificação como estratégia pedagógica: estudo de elementos dos games aplicados em processos de ensino e aprendizagem. Dissertação (Mestrado) Programa de Pós-Graduação em Educação, Universidade de Caxias do Sul, Caxias do Sul, 2013.

HAMARI, Juho.; KOIVISTO, Jonna.; SARSA, Harri. Does Gamification Work? A Literature Review of Empirical Studies on gamification. In: INTERNATIONAL CONFERENCE ON SYSTEM SCIENCES, 47, 2014, Hawaii. Proceedings... New York: IEEE, 2014. p. 3025-3034. DOI: https://doi.org/10.1109/HICSS.2014.377.

JEWETT, John; SERWAY, Raymond. Física para cientistas e engenheiros. 8 ed. São Paulo: Cengage Learning, 2012. v. 4.

KAPP, Karl. The Gamification of Learning and Instruction: Game-based Methods and Strategies for Training and Education. Pfeifer, Wiley USA, 2012.

KELLER, John. Motivational Design for Learning and Performance: The ARCS Model Approach. Springer, 2009.

KAMINSKI, Márcia Regina; SILVA, Denis Antônio; BOSCARIOLI, Clodis. Integrando Educomunicação e gamificação como estratégia para ensinar sustentabilidade e alimentação saudável no $5^{\circ}$ ano do Ensino Fundamental. Revista Prática Docente. v. 3, n. 2, p. 595-609, 2018. DOI: http://dx.doi.org/10.23926/RPD.2526-2149.2018.v3.n2.p595-609.id259.

MCGONIGAL, Jane. Reality is broken: why games make us better and how they can change the world. Nova Iorque: The Penguin Press, 2011.

MOREIRA, Marco Antônio. Grandes desafios para o ensino da Física na educação contemporânea. Revista do Professor de Física, v.1, n. 1, p.1-13, 2017. Disponível em: http://periodicos.unb.br/index.php/rpf/article/view/25190. Acesso em: 01 abril. 2018. 
MULLER, Maykon Gonçalves; ARAUJO, Ives Solano; VEIT, Eliane Angela; SCHELL, Julie. Uma revisão da literatura acerca da implementação da metodologia interativa de ensino Peer Instruction (1991 a 2015). Revista Brasileira de Ensino de Física, v. 39, n. 3, e3403, 2017. DOI: https://doi.org/10.1590/1806-9126-rbef-2017-0012.

POFFO, Marcio. Utilização da gamificação para motivar a aprendizagem: um estudo de caso em engenharia de software. Dissertação (Mestrado) - Programa de Pós-Graduação em Computação, Universidade do Vale do Itajaí, 2016.

SALES, Gilvandenys Leite; CUNHA, Joana Laysa Lima; GONÇALVES, Alexandra Joca; SILVA, João Batista; SANTOS, Rubens Lopes. Gamificação e ensinagem híbrida na sala de aula de física: metodologias ativas aplicadas aos espaços de aprendizagem e na prática docente. Revista Conexões: ciência e tecnologia, v. 11, n. 2, p. 45 - 52, 2017. Disponível em: http://conexoes.ifce.edu.br/index.php/conexoes/article/view/1181. Acesso em: 02 jun. 2017. DOI: https://doi.org/10.21439/conexoes.v11i2.1181.

SAVI, Rafael. Avaliação de jogos voltados para a disseminação do conhecimento. Tese (Doutorado) - Programa de Pós-Graduação em Engenharia e Gestão do Conhecimento, Universidade Federal de Santa Catarina, Florianópolis, 2011.

SILVA, João Batista; ANDRADE, Maria Helena; OLIVEIRA, Rannyelly Rodrigues; SALES, Gilvandenys Leite; ALVES, Francisco Regis Vieira. Tecnologias digitais e metodologias ativas na escola: o contributo do Kahoot para gamificar a sala de aula. Revista Thema, v. 15, n. 2, p. 780-791, 2018. Disponível em:

http://revistathema.ifsul.edu.br/index.php/thema/article/view/838. Acesso em: 24 maio 2018. DOI: http://dx.doi.org/10.15536/thema.15.2018.780-791.838.

SILVA, João Batista; SALES, Gilvandenys Leite. Gamificação aplicada no ensino de Física: um estudo de caso no ensino de óptica geométrica. Revista Acta Scientiae, v. 19, n. 5, p. 782 - 798, 2017a. Disponível em :

http://www.periodicos.ulbra.br/index.php/acta/article/view/3174. Acesso em: 20 jun. 2019.

SILVA, João Batista; SALES, Gilvandenys Leite. Um panorama da pesquisa nacional sobre gamificação no ensino de Física. Tecnia: Revista de Educação, Ciência e Tecnologia do IFG, v. 2, n. 1, p. 105-121, 2017b. Disponível em:

http://revistas.ifg.edu.br/tecnia/article/view/172. Acesso em: 30 jun. 2019.

TODA, Armando Maciel; SILVA, Alan Pedro; ISOTANI, Seiji. Desafios para o planejamento e implantação da gamificação no contexto educacional. Revista Novas

Tecnologias na Educação - RENOTE, v. 15, n. 2, 2017. Disponível em: http://seer.ufrgs.br/index.php/renote/article/view/79263. Acesso em: 20 jun. 2019.

TOLENTINO, Analyn; ROLEDA, Lydia. Learning Physics the Gamified Way. In: THE DLSU RESEARCH CONGRESS, 1, 2017, Manila. Proceedings... Philippines: DLSU, 2017, p. 1-6. Disponível em: http://www.dlsu.edu.ph/conferences/dlsu-research-congressproceedings/2017/LLI/LLI-I-019.pdf. Acesso em: 20 mai. 2019.

VIANNA, Ysmar; VIANNA, Maurício.; MEDINA, Bruno.; TANAKA, Samara.

Gamification, Inc.: como reinventar empresas a partir de jogos. Rio de Janeiro: MJV Press, 2013. 
YIN, Robert. K. Estudo de caso. Planejamento e métodos. Porto Alegre: Bookman, 2001. ZICHERMANN, Gabe; CUNNINGHAM, Christopher. Gamification by Design. Implementing Game Mechanics in Web and Mobile Apps. Canada: O'Reilly Media, 2011.

Recebido em: 26 de fevereiro de 2020. Aprovado em: 17 de abril de 2020. 